Review Article

\title{
PRETERM RUPTURE OF MEMBRANES: THE VITAMIN C FACTOR
}

\section{*J.A. Osaikhuwuomwan}

*Department of Obstetrics and Gynaecology, University of Benin Teaching Hospital, PMB 1111, Benin City, Nigeria

\section{Correspondence:}

Osaikhuwuomwan J.A

Dept of Obstetrics and Gynaecology

University of Benin Teaching Hospital, Benin City, Nigeria.

E-mail: Jagbons1@yahoo.com

Preterm prelabour rupture of membranes (PPROM) is one of the major factors that have been found to correlate with adverse pregnancy outcome $^{1-8}$. It remains a critically important clinical and public health problem. PPROM is a leading cause of preterm delivery with a third of all preterm births resulting from preterm $\mathrm{PROM}^{1-4,9-10}$. It is associated with considerable increase in adverse maternal, foetal and neonatal risk $^{7}$. The adverse perinatal outcome following preterm delivery is huge, accounting for up to $70 \%$ of perinatal mortality worldwide ${ }^{8,11-13}$. A perinatal mortality rate of $52 \%$ as a result of PPROM has been reported in Nigeria ${ }^{7}$. Despite the challenge posed by PPROM to obstetric and paediatric care, its aetiology and thus preventive and therapeutic strategies to control the condition remains elusive ${ }^{13-14}$.

The incidence of PPROM varies for different countries and population. This is because of the multiple risk factors that have been associated with PROM and also the non-uniformity in reporting and distinguishing between preterm PROM and PROM at term ${ }^{10,13,15-16}$. Some authors have reported an association with the socioeconomic status of the population studied with the incidence higher in the most deprived segment of society ${ }^{15}$. Other studies found a statistically significant higher incidence amongst black population even after adjusting for socioeconomic and maternal medical risk factors ${ }^{16-18}$. The incidence of preterm PROM across the world population ranges from $0.7 \mathrm{i} 3.5 \%$ of all births ${ }^{2,4.10,12,14,16,19}$. An incidence of $2.5 \%$ was reported in southern Nigeria ${ }^{7}$.

The cause of preterm PROM is unknown but the pathophysiology appears to be multifactorial ${ }^{3,4}$. In any given patient one or more pathophysiologic processes may be evident. Choriodecidual infection or inflammation appears to play an important role in aetiology of preterm PROM, with rupture of membranes being attributed to increasing physical stress that weakens $i t^{3,4,5}$. Recent evidence suggests that membrane rupture is also related to biochemical processes such as abnormalities in collagen structure and formation as well as increased oxidative stress ${ }^{3,20}$. In support of this an imbalance between synthesis and degradation of collagen within the extracellular matrix of the chorioamniotic membrane induced by an increased expression and activity of various matrix metalloproteinases has been 
implicated in the aetiology of PPROM $^{21-23}$.

Micronutrients deficiencies that affect collagen formation have been shown to alter collagen structure and this has been associated with an increased risk of preterm $\mathrm{PROM}^{3,5,24}$. Researches in this regard have investigated the role of Vitamin $C^{5,25-27}$. Vitamin C or Ascorbic Acid is a water soluble vitamin and one of the body $\hat{\mathbf{s}}$ naturally occurring antioxidant that is not synthesized by humans ${ }^{28-30}$. Ascorbic acid oxidizes readily to dehydroascorbic acid which passes readily through the membranes where it acts to protect the body against degenerative processes resulting from oxidative stress ${ }^{29,31}$. Dietary deficiencies of Vitamin $C$ leads to scurvy which is characterized by collagen weakness and capillary haemorrhage $^{29,30}$. Functioning as a micronutrient/antioxidant Vitamin C directly stimulates collagen synthesis through activation of multiple genes. In addition ascorbic acid serves to strengthen and stabilize collagen by acting as an enzymatic cofactor to the enzymes, lysyl hydroxylase and prolyl hydroxylase, which are required for synthesis of hydroxyproline and hydroxylysine. Collagen requires hydroxyproline bridges across the triple helix to provide stability to it ${ }^{29,30}$. Ascorbic Acid as an antioxidant acts as a reducing agent by delivering a hydrogen atom with its single electron to the single unpaired electron in the outer ring of reactive oxygen species (ROS). The ROS now with paired electron is stabilized ${ }^{29}$. Ascorbic Acid also causes down regulation of the metalloproteinase-2(MMP-2)

transcriptional factor, thus suppressing the expression of MMP-2 and blocking its tissue damaging effect ${ }^{29}$. Thus Vitamin $\mathrm{C}$ is thought to participate in the equilibrium between synthesis, stability and degradation of collagen and this may be critical in reducing the occurrence of preterm PROM ${ }^{16,29,32}$.

Vitamin $C$ cannot be synthesized by the body hence it is only gotten from dietary sources or supplementation $^{32}$. Dietary or supplemental dose of $60-100 \mathrm{mg}$ of Vitamin $\mathrm{C}$ has been recommended to maintain normal plasma levels ${ }^{28,31}$. Assessing micronutrients status in human sample is challenging due to their labile nature, however results are validated by the method of assay ${ }^{31}$. Vitamin $\mathrm{C}$ can be measured in plasma, white blood cells or urine. In humans the determination of Vitamin $C$ status is commonly done using plasma ${ }^{31}$. Fasting plasma samples are collected and preserved quickly by freezing in order to improve result reliability ${ }^{31,33}$. The method of assay could be by chromatography, spectrophotometry or automated enzyme procedure.. The commonest assay method used is the reverse phase high performance liquid chromatography ${ }^{31,33}$. Reference values for Vitamin $C$ seems to be influenced by the assay method and study design, albeit the widely accepted reference value for normal of fasting samples is $26.1-84.6 \mu \mathrm{mol} / \mathrm{l}(>0.6 \mathrm{mg} / \mathrm{dl}$, $>20 \mu \mathrm{g} / 10^{8}$ cells, $>114 \mathrm{nmol} / 10^{8}$ cells), while for deficiency state is a value of $<11 \mu \mathrm{mol} / \mathrm{l}\left(<0.2 \mathrm{mg} / \mathrm{dl}\right.$, $<10 \mu \mathrm{g} / 10^{8}$ cells, $<57 \mathrm{nmol} / 10^{8}$ cells) ${ }^{31,33-37}$. Two separate studies in northern and southern Nigeria assessing the Vitamin C plasma levels amongst pregnant and non pregnant women reported values within the international reference range ${ }^{38-39}$. These local studies further corroborated previous reports, by demonstrating a fall in Vitamin $\mathrm{C}$ levels in pregnancy and a steady decline observed with increasing gestational age $\mathrm{ag}^{28,36-42}$. It has been suggested that the lower levels observed in pregnancy when 
compared to non pregnant controls may be due to the physiologic hemodilution in pregnancy, increased demand from oxidative stress or a

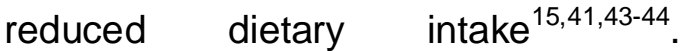
Pregnancy has also been shown to promote oxidative stress ${ }^{28,38,45-46}$. A study in University of Benin Teaching Hospital on the effect of pregnancy on antioxidant capacity demonstrated that the total antioxidant capacity was low amongst pregnant women ${ }^{45}$. These studies proposed that use of exogenous antioxidant supplement during pregnancy to mitigate against this oxidative stress may be necessary to prevent pregnancy complications ${ }^{38,39,41,44-46}$. Despite these beneficial effects of antioxidants in pregnancy more detailed and specific research is still advocated ${ }^{45,47}$. Therefore deficiency of Vitamin $\mathrm{C}$ has been hypothesized to play a role in preterm $\mathrm{PROM}^{16,21,32}$.

The role of Vitamin $\mathrm{C}$ in PROM/preterm delivery has been previously investigated. Pioneer work in this regard dates back to 1964 when Wideman and colleagues ${ }^{25}$ reported an association between low ascorbic acid levels and preterm rupture of foetal membranes. Since then, other studies have examined the role of Vitamin $\mathrm{C}$ in maintaining membrane integrity, dietary intake and also emphasis on measurement of ascorbic acid concentration in plasma, leukocyte and cord blood as it affects preterm PROM and preterm birth $27,28,31,48-49$.

Kanayama and colleagues were able to substantiate Widemanîs work by demonstrating low collagen content in the membranes of patients with $\mathrm{PROM}^{26}$. Their finding was corroborated by in-vitro studies carried out by Plessinger et $a l^{27}$ who noted that excessive damage to in-vitro amniotic epithelium and collagen results from exposure to hypochlorous acid that was dose related. They went further to confirm that pre-treatment with Vitamin $\mathrm{C}$ and $\mathrm{E}$ (as antioxidants) prevented damage in all cases.

Woods $^{50}$ in his review of reactive oxygen species and preterm PROM hypothesized that reactive oxygen generated by the bodycs response to diverse insults, such as infection, smoking and bleeding could activate collagenolytic enzymes and impair foetal membrane integrity. $\mathrm{He}$ proposed that supplementation with Vitamin $C$ may substantially reduce the risk of PPROM and thus suggested the prospects of therapeutic trials ${ }^{23,29}$. Another in-vitro study done showed proportional degradation of collagen the lower the Vitamin C concentration $^{51}$. Similar studies in Nigeria observed that Vitamin $C$ may protect against lipid peroxidation and hypochlorus induced damage in pregnant women ${ }^{46}$. These studies are however in-vitro studies and may not reflect exactly the in-vivo effects of Vitamin C. In a nested case control study among a cohort of pregnant women, those with PROM had decreased Vitamin C concentration and were also shown to have quantitative deficiency and abnormal crosslinking of collagen ${ }^{22}$. The assumptions from this study were however limited by the small sample size. Barrett and colleagues evaluating the potential role of ascorbic acid in prevention of PROM found only a positive association between low amniotic fluid Vitamin $\mathrm{C}$ and not serum Vitamin $\mathrm{C}$ as an important determinant of $\mathrm{PROM}^{48}$

On this background, Casanueva et al ${ }^{15,52-54}$ under-took several studies to establish Vitamin $C$ status in pregnancy and its association with premature rupture of membranes. They had observed altered pattern of 
collagen synthesis and diminished Vitamin C concentration in pregnancy which was associated with subsequent occurrence of PPROM ${ }^{54}$. They went further to use PROM as a functional assessment to establish cut off points for Vitamin C throughout pregnancy ${ }^{53}$. Vitamin $C$ levels were determined by the reverse phase high performance liquid chromatography and it was found that plasma Vitamin $\mathrm{C}$ concentration below a critical level of $18 \mu \mathrm{g} \quad(102 \mathrm{mmol}) / 10^{8} \quad$ cells is associated with a substantially increased risk of PROM ${ }^{24,34,53,55}$.

The effectiveness of Vitamin $\mathrm{C}$ at a dose of $100 \mathrm{mg} /$ day in preventing PPROM was evaluated in a randomized double-blind placebo controlled trial where it was found that $100 \mathrm{mg}$ of Vitamin C per day was sufficient to maintain leukocyte ascorbic acid concentration at a level above $18 \mu \mathrm{g} / 10^{8}$ cells and this can protect against PPROM $^{52}$. Furthermore it was noted that though daily supplementation with $100 \mathrm{mg}$ Vitamin C after 20 weeks gestation effectively reduced the incidence of PROM there was no significant difference in Vitamin C concentration between the two groups and mean plasma Vitamin C concentration decreased throughout pregnancy in both groups ${ }^{52}$.

Borna and colleagues in addition found in their study a statistically significant increase in latency period for those that had Vitamin $C$ and $E$ supplementation after preterm PROM $^{56}$. Similarly in another prospective cohort study of 2,064 pregnant women it was found that women with preconception total Vitamin C intake of less than $10^{\text {th }}$ percentile had twice the risk of preterm delivery because of PROM and thus it has been suggested that vitamin supplementation may be a valuable interventional strategy ${ }^{57}$.

On the other hand, in a randomised double-blind placebo-control trial; where antioxidant supplementation and PROM was planned secondary analysis. It was observed contrary to expectation that Vitamin $C$ caused an increase in the incidence of $\mathrm{PROM}^{58}$. They concluded that empirical use of antioxidant supplementation should be discouraged and future investigations on antioxidants supplement to prevent PROM should be done with caution. In this study, the population investigated were mainly chronic hypertensives or those with history of previous preeclampsia and this may have flawed the results obtained. Furthermore, the high dose of antioxidant supplements used and the pharmacology of the selected drug were limitations in the study which makes it difficult to challenge the validity of previous work by Casanueva and co-workers ${ }^{52}$ supporting the role of Vitamin $C$ supplementation to prevent PROM. Another randomized double-blind placebo-controlled trial of ascorbic acid for the prevention of preterm labour did not show any significant change in Vitamin C levels or incidence of preterm labour with Vitamin C supplementation and they concluded that the proposed effect of Vitamin C supplementation may only be apparent in the patient with a bonafide Vitamin C deficiency ${ }^{32}$. They suggested the prospects of performing the study in a more rural population.

In Nigeria and sub-Saharan Africa research efforts have focussed on assessment of Vitamin C status and antioxidant capacity in pregnancy. These studies reported increased oxidative stress in pregnancy, inadequate dietary intake and low plasma Vitamin C levels amongst pregnant Nigerian women ${ }^{38-41,43-46}$. 
The work done in UBTH by Idogun et al, found that total antioxidant capacity was lower in pregnancy and supported the need for antioxidant supplementation in pregnancy $^{45}$; they recommended the need for more detailed research on specific antioxidants.

There exists an obvious paucity of research on the relationship between preterm PROM and Vitamin C in subSaharan Africa (where ironically the incidence is commoner), majority of published work in our locale have been on bacteriology of PROM and antibiotic use $\mathrm{e}^{6,7,11-13,16-18,59-60}$. The dearth of research effort on prevention of preterm PROM in our environment is worrisome, owing to the fact that while in the developed society the survival rates of premature babies have greatly improved as a result of improved neonatal care ${ }^{14}$, the reverse is the case in developing countries where neonatal care especially for preterm babies is quite challenging, still expensive and beyond the reach of most people. Other factors like ignorance, poverty and even ф́ower failureôimpact negatively on the care of preterm neonates in our locale ${ }^{11,14}$, thus perpetuating the high perinatal mortality rate of over $50 \%$ often reported $^{7,12,17}$.

The devastating consequences of preterm PROM and prematurity makes it necessary to develop health strategies aimed at improving outcome by predicting, preventing and treating preterm PROM and preterm labour. Hence it becomes imperative to carry out studies in our locale that seek to evaluate the relationship between preterm PROM and Vitamin C concentration in blood. If this is established, advocacy could be made for strategies such as Vitamin C supplementation that represents a safe, non-invasive and cost effective approach to the prevention of preterm PROM and its adverse consequences.

\section{REFERENCES}

1. Goldenberg RL, Lams JD, Mercer BM, The preterm prediction study: The value of new VS standard risk factors in predicting early and all spontaneous preterm births. Am J Public Health. 1998; 88: 233-238.

2. Premature rupture of membranes. ACOG Technical bulletin NO. 115. 1988. Washington D.C.

3. Parry S, Strauss JF. Mechanisms of disease: premature rupture of the fetal membranes. N. Engl. J. Med 1998; 338: 663-70.

4. Mercer B. Preterm premature rupture of the membranes. Obstet Gynaecol. 2003; 101(1): 178-193.

5. McParland PC and Taylor DJ. Preterm prelabour rupture of the membranes. In Bonnar $J$ and Dunlop W (ED) Recent advances in Obstetric and Gynaecology. 2005; 23(3): 27-38.

6. Aboyeji AP, Abdul IF, ljaiya MA, Nwabuisi $C$ and Ologe MO. The bacteriology of prelabour rupture of membranes in Nigeria Teaching Hospital J Obstet Gynaecology. 2005; 25(8): 761-764.

7. Obi SN and Ozumba BC. Preterm premature rupture of foetal membranes: The dilemma of management in a developing nation. J Obstet Gynaecol. 2007; 27(1): 37-40.

8. Medina TM and Hill DA. Preterm premature rupture of membranes. 
Diagnosis and management. Am Fam. Physician. 2006; 73: 659-666.

9. Goldenberg RL, Culhane. JF, lams JD and Romero R. Epidemiolgoy and causes of preterm birth. Lancet 2008; 371(9606): 75-84.

10. Ferguson S.E., Smith GN, Salenietes ME, Windrim $R$ and Walker MC. Preterm premature rupture of membranes. Nutritional and socioeconomic factors. Obstet Gynaecol. 2002; 100(1): 1250 ï 1286.

11. Etuk SJ, Etuk SI, Oyo-ita AE. Factors influencing the incidence of preterm birth in Calabar Nigeria. Nig $\mathrm{J}$ of physiological science. 2005; 20(1-2): 63-68.

12. Nkyekyer K, Enweronou-Laryea and Boafor T. Singleton preterm births in Korle $\mathrm{Bu}$ Teaching Hospital. Accra, Ghana. Origins and outcomes. Ghana Med J. 2006; 40(3): 93-98.

13. Menon R. Spontaneous preterm birth. A. clinical dilemma; Etiologic, pathophysiologic and genetic heterogeneities and racial disparity. Acta Obstet Gynaecol Scand. 2008; 87(6): 590-600.

14. Aziken ME. Preterm labour and delivery in Okpere EE (ED) clinical obstetrics. Uniben Press. 2003; 203-209.

15. Casanueva E, Vadillo-ortega $F$, Pfeffer $F$ and Tejero E. Vitamin C and premature rupture of chorioamniotic membranes. Nutr Res. 1998; 18(2): 241-245.

16. Shen TT, Defranco EA, Stamillo DM, Chang JJ and Muglia LL.. A population based study of race specific risk for preterm premature rupture of membranes. AM $\mathrm{J}$ Obstet Gynaecol. 2008; 199 (4): $373 e_{1}-e_{7}$.

17. Savitz DA, Blackmore CA, Thorp JM Epidemiologic characteristics of preterm delivery etiologic heterogeneity. AM J Obstet Gynaecol. 1991; 164(2): 467-71.

18. Wang H, Parry S, Macones G, Samuel $M$ and Kuivaniemi $H$. et al. A functional SNP in the promoter of the SERPINH gene increases risk of preterm premature rupture of membrane in African Americans. PNAS 2006; 103(36): 1346313467.

19. Astrat T, Lewis DF, Garitse TJ, Major CA, Nageotte $M$ et al. Rate of recurrence of preterm premature rupture of membranes in consecutive pregnancies. AM J Obstet Gynaecol. 1991; 165(4): 1111-5.

20. Kundtson E.J, Smith K, Mercer BM, Miodovnik M, Thurnau GA. et al. Serum homocysteine levels after preterm premature rupture of the membranes. Am J Obstet Gynacol. 2004; 191(1): 537-41.

21. Casanueva E, Ripoll C, MezaCamacho C, Coutino J, Ramirezperedo J, and Paira A. Possible interplay between Vitamin $\mathrm{C}$ deficiency and prolactm in pregnant women with premature rupture of membranes. Facts and hypotheses. Med Hypotheses 2005; 64(2): 241-247.

22. Tejero E, Perichart O, Pfeffer F, Casanueva E, Vadillo-ortega $F$. Collagen synthesis during pregnancy, Vitamin C availability and risk of premature rupture of 
foetal membranes. Int J. Gynaecol Obstet. 2003; 81: 29-34.

23. Fortunato SJ, Menon R. Distinct molecular events suggest different pathways for preterm labour and premature rupture of membranes, AM J Obstet Gynaecol. 2001; 184: 1399-405.

24. Ramakrishnan U. Manjrekar $R$, Rivera J, Gonzales-Cossio T and Martorell R. Micronutrients and pregnancy outcome. A review of Literature. Nutrition Research 1999; 19(1): 103-159.

25. Wideman GL, Baird GH and Bolding OT. Ascorbic acid deficiency and premature rupture of fetal membranes. Am J Obstect Gynaecol 1964; 88: 592-5.

26. Kanayama N, Terao T, Kawashima $\mathrm{T}$, Horiuchi $\mathrm{K}$ and Fujimoto $\mathrm{D}$ et al Collagen types in normal and prematurely ruptured amniotic membranes. J Obstet Gynaecol 1985; 153: 899-903.

27. Plessinger MA, Woods JR, Miller RK. Pretreatment of human amnion-chorion with Vitamin $\mathrm{C}$ and $\mathrm{E}$ prevents hypochlorus acid induced damage Am J Obstet Gynaecol. 2000; 183(1): 979-85

28. Mathews F and Neil A. Antioxidants and preterm prelabour rupture of the membranes. BJOG. 2005; 112(5): 588-594.

29. Woods JR Jnr. Plessinger MA, Miller RK. Vitamin C and E: Missing links in preventing preterm premature rupture of membranes? Am J Obstet Gynaecol. 2001; 185(1): 5-10.
30. Lee W, Davis KA, Reffmer RL and Labbe RF. et al. Ascorbic acid status: biochemical and clinical considerations. Am J. Clin Nutr. 1988; 48: 286-290.

31. Salminen I and Alfthan G. Plasma ascorbic acid preparation and storage for epidemiological studies using TCA precipitation. Clinical biochemistry. 2008; 41: 723-727.

32. Steyn PS, Odendaal HJ, Schoeman J, Stander C, Fanie N et al. A randomized double-blind placebo-controlled trial of ascorbic acid supplementation for the prevention of preterm labour. $\mathrm{J}$ Obstet Gynaecol. 2003; 23(2): 150155.

33. Lee W, Roberts SM and Roberts FL. Ascorbic acid determination, an automated enzymatic procedure. Clin Chemistry. 1997; 43: 154-157.

34. Emadi-Konjin $P$, Verjee $Z$, Levin $A$, Adeli K. Measurement of intracellular Vitamin C levels in human lymphocytes by reverse phase high performance liquid chromatography. Clinical biochemistry. 2005; 38(5): 450-456.

35. Nino BV and Shaw N. Vitamins. In: Teitz (ed) fundamentals of clinical chemistry. 1987: Philadelphia. London.

36. Hampl JS, Taylor C, Johnston CS. Vitamin $C$ deficiency and depletion in the United States. The third National health and nutrition survey, 1988-1994. Am J of Pub Health. 2004; 94(5): 870-875.

37. Levine M, Conry-Cantilena C, Wang Y, Welch NW, Washko PW. et al. Vitamin C pharmacokinetics in healthy volunteers: evidence for 
a recommended dietary allowance. PNAS. 1996; 93: 3704-3709.

38. Hassan Gl and Onu AB. Total serum Vitamin $C$ concentration in pregnant women; Implications for a healthy pregnancy. Rev Bras Saude. Matern. Infant, Recife. 2006; 6(3): 293-296.

39. Nwagha UI and Ejezie FE. Serum ascorbic acid levels during pregnancy in Enugu, Nigeria. J. Coll of Medicine. 2005; 10(1): 4345.

40. Therieko PA and Ettes SX. Plasma ascorbic acid levels in Nigerian mothers and newborn. J. Trop Ped. 1981;27: 263-266.

41. Awoyelu CO, Agharanya JC, Oguntibeju OO. Ascorbic acid status in third trimester of pregnancy, at delivery and in cord blood. Indian J Clin Biochem. 2004; 19(1): 54-56.

42. Jacob RA. Vitamin $C$ function and status in chronic disease. Nutrition in clinical care. 2002; 5(2): 66-74.

43. Oguntibeju OO. The biochemical, physiological and therapeutic roles of ascorbic acid. African J Biotech. 2008; 7(25): 4700-4705.

44. Ojofeitimi EO, Ogunjuyigbe $P O$, Sanusi RA, Orji EO, Akinlo,SA. et al. Poor dietary intake of energy and retinol among pregnant women: Implications for pregnancy outcome in southwest Nigerian. Pak J Nutr. 2008; 7(3): 480-484.

45. Idogun ES, Odiegwu ME, Momoh SM, Okonofua FE. Effects of pregnancy on total antioxidant capacity in Nigerian women. Pak J. Med Sci. 2008; 24(2): 292-295.
46. Olayaki LA, Ajao SM, Jimoh GA, Aremu IT, and Soladoye AO. Effect of Vitamin $C$ on malondialdehyde (MDA) in pregnant Nigerian women. J Basic Appl Sci. 2008; 4(2): 105-108.

47. Rumbold $A$ and Crowther CA. Vitamin C supplementation in pregnancy. Cochrane database of systematic reviews. 2005; 18(2): CD004072

48. Barrett BM, Sowell A, Gunter E and Wang M.. Potential role of ascorbic acid and beta carotene in the prevention of preterm rupture of fetal membranes. Int $\mathrm{J}$ Vitam Nutr Res. 1994; 64: 192-7.

49. Erichsen HC, Mulherin Engel SA and Eck PK. Genetic variation in the sodium-dependent Vitamin $\mathrm{C}$ transporters, SLC23A1 and SLC23A2 and risk of preterm delivery. AM J Epid. 2006; 163(3): 245-254.

50. Woods JR Jnr. Reactive oxygen species and preterm premature rupture of membranes: a review. Placenta. 2001; Suppl A: 538-44.

51. Vadillo-ortego F, Pfeffer F, Bermejo ML, Hernandez MA, Beltran MJ. et al. 92 Dietetic factors and premature rupture of fetal membranes. Effects of Vitamin C on collagen degradation in the chorio-amnion. Ginecologia $y$ Obstetricia de Mexico.1995; 63: 158-162.

52. Casanueva E, Ripoll C, Tolentino $\mathrm{M}$, Morales $\mathrm{R}$, Pfeffer $\mathrm{F}$ et al. Vitamin C supplementation to prevent premature rupture of the Chorioamiotic membranes: A randomized trial. Am J Clin Nutr. 2005; 81: 859-63. 
53. Casanueva E. Polo E, Tejero E, Meza .C. Premature rupture of amniotic membrane as a functional assessment of Vitamin $\mathrm{C}$ status during pregnancy. Ann NY Acad Sci 1993; 678: 369-370.

54. Casanueva E, Avila-Rosas H, Polo E, Tejero E, Narcio-Reyes ML. et al Vitamin C status, cervico-vaginal infection and premature rupture of amniotic membranes. Arch. Med. Res. 1995; 26(suppl): s149-s152

55. Casanueva E, Magana L, Pfeffer F, Baez A. Incidence of premature rupture of membranes in pregnant women with low leukocyte levels of Vitamin C. Eur J. Clin Nutr 1991; 45: 401-5.

56. Borna S, Borna H, Daneshbodie B. Vitamin $C$ and $E$ in the latency period in women with preterm premature rupture of membranes. Int. J. Gynaecol Obstet 2005; 90(1): 16-20.
57. Siega-Riz AM, Promislow JH, Savitz DA, Thorp JM and Mcdonald $\mathrm{T}$ Vitamin $\mathrm{C}$ intake and the risk at preterm delivery Am $\mathrm{J}$ Obstet Gynaecol. 2003; 189(2): 519-525

58. Spinnato JA II, Freire S, Pinto e Silva JL, Rudge MV, Martins-Costa $S$ et al. Antioxidant supplementation and premature rupture of the membranes. A planned secondary analysis. Am J. Obstet Gynaecol 2008; 199(4): 433 e1-e8.

59. Oboro VO, Adekanle BA, Apantaku BD and Onadipe OA. Preterm prelabour rupture of membranes. Effect of chorioamnionitis on overall neonatal outcome. J Obstet Gynaecol. 2006; 28(8): 740-743.

60. Adesiji YO, Taiwo SS, Adekunle DA, Oboro VO, Fayemiwo SA. et al. Bacteria vaginosis and pregnancy outcome in Osogbo, Nigeria. Res J Med Sci. 2007; 1(4): 195-198. 